\title{
Fatigue behaviour and detailing of slotted tubular connection
}

\author{
C. Baptista \\ IST Lisbon, GRID Engineering, Portugal
}

L. Borges

ISISE, Department of Civil Engineering, University of Coimbra, Portugal

S. Yadav \& A. Nussbaumer

ICOM - Steel Structures Laboratory, EPFL, Lausanne, Switzerland

ABSTRACT: Tubular elements are used in steel structures not only for bracing of other members but also as cross girders diaphragms. They are a competitive solution both due to the lightweight and structural efficiency. Slotted tube-to-plate connections are the natural and most common choice. However, fatigue design of the abrupt transition and differences in the stiffness corresponding to the welded connection, is a critical part of the design. Although such a fatigue connection is classified in different standards (e.g. EN1993-1-9, IIW recommendations), no guidance is given on the specific detailing. In this paper, the existing fatigue datasets for this connection are reviewed. An assessment of the different fatigue details constituting the connection (welds end, hole, etc.) using FEM models and the notch stress method is then made. The results are compared with the experiments and recommendations are issued in order to achieve the best fatigue performance.

\section{INTRODUCTION}

\subsection{Detail category (value at 2 million cycles)}

In slotted tubular connections, the tube may either be a circular (CHS) or a rectangular (RHS) hollow section, as shown in figure 1. Regarding the connection, its fatigue behaviour can be influenced by: the detailing of the welds between the tube and the plate, the gusset plate geometry, the tube chamfering, and probably the geometrical ratios of the connected parts (diameter/thickness of CHS, RHS, thickness ratio of plate and tube). For this or any other similar connections, the detail categories differ from standard to standard and not all consider the same influencing parameters.

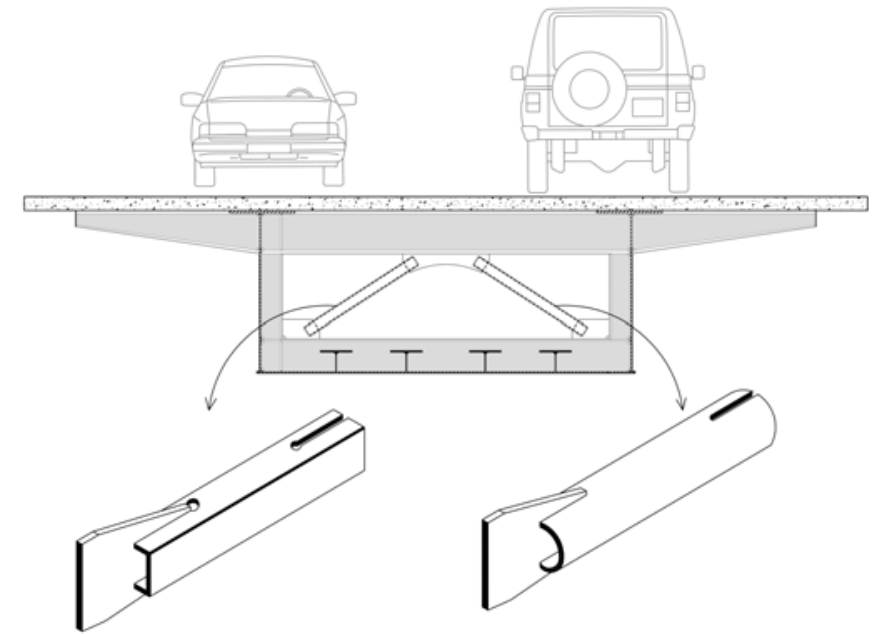

Figure 1. Illustration of slotted tubular connections with CHS or RHS (each tube can be with or without hole)

EN1993-1-9:2005 classifies it (table 8.6, detail 2) for circular hollow sections (CHS) as CAT 71 (or CAT 63 for chamfered angles higher than $45^{\circ}$ ), but only for tubes with wall thicknesses less or equal to $12.5 \mathrm{~mm}$; no limit on the tube diameter is given. The connection includes open holes at the end of the slit, a feature that facilitates fabrication and avoids having a non-detectable crack starting from the root of the weld. The recommendation for such a feature originates from Profs. J.W. Fisher and A. Pense, following a failure in a crane boom without warning; with open holes, fatigue cracking is visible if it develops (Fisher, 2009). However, the fatigue strength of the connection with open holes as CAT 71 cannot be taken as granted, as indeed no tests in high cycle fatigue were carried out on this detail.

In the IIW recommendations, a slotted CHS tube welded to plate is classified as a function of the tube diameter and plate thickness:

- FAT $63\left(d \leq 200 \mathrm{~mm}, t_{\mathrm{p}} \leq 20 \mathrm{~mm}\right)$

- FAT $45\left(d>200 \mathrm{~mm}, t_{\mathrm{p}}>20 \mathrm{~mm}\right)$

No open holes are shown and no requirement on the chamfered angle is given.

DNV recommended practice (DNVGL-RP-0005, 2014) identifies this connection as tubular joint with gusset plate. It recommends the use of FEA and hot spot stress method to design against fatigue this detail. DNV differentiates between circular and rectangular hollow sections and also considers the closing of the tube end with plates to prevent water from getting in (sealing plates). The classification in hot spot stress is 90 for the end of the weld of the plate on the tube, which is often the critical spot.

BS7608, AISC and CIDECT design guide 8 (fatigue) do not have this detail categorized. Instead, in many codes, a "tube gusseted connection" detail is included, see section 3.2. 
To summarize, the category and limits of application are confusing for this detail, not to mention the lack of guidance for computing the relevant stress in some codes. Only the tube chamfering angle, some geometrical limits of the connected parts (tube diameter and plate thickness) and the presence of open holes are differently specified. It is surprising that the detailing of the welds between the tube and the gusset plate is not part of the specifications.

\subsection{Notch stress method}

Finite element methods of increasing complexity (called local approaches) and devoted to analysing details under fatigue have emerged over the past years. In order to use only one S-N curve, the preferred method today is the effective notch stress method (Radaj 1990) (Fricke 2008). By modelling the local detail geometry, one can consider all global and local stress concentration effects within the model. The S-N curve provides then the intrinsic fatigue resistance of a weld toe or root with its microstructural imperfections. Thus, the method relies on the definition of a reference resistance fatigue curve, differentiating only between the weld types (E. Niemi et al. 2006). In order to get a finite and mesh independent peak stress value, all weld toes and roots of the connection are modelled with a fictitious notch radius of $1 \mathrm{~mm}$, see fig. 2. This fictitious notch radius has to be added to the actual notch radius, which is usually assumed to be zero in a conservative way. Therefore it is recommended to assume generally $r_{\text {ref }}=1 \mathrm{~mm}$ for design purposes. The result is an effective notch stress or, if related to the nominal stress, a fatigue notch factor $K_{\mathrm{f}}$ (Fricke 2008). This approach together with a design reference fatigue curve of FAT $225(225 \mathrm{MPa}$ at 2 million cycles and $\mathrm{m}=3$ ) for steel, has been first included in the IIW Recommendation in 1996 (Hobbacher, 1996), valid for all weld types. The application to welded plate details (failing from the toe or the root) has extensively been investigated in particular for the ship industry (Fricke et al. 2002, Fricke 2012).

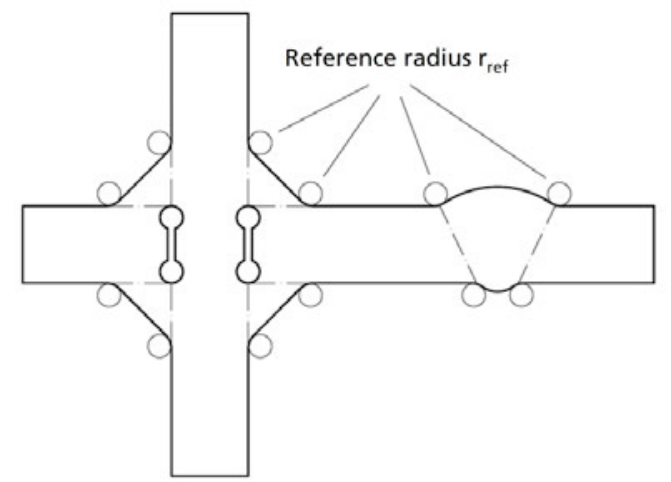

Figure 2. Applications of reference radii for the calculation of notch stresses (Hobbacher 1996).

\section{ANALYSIS OF FATIGUE DATASETS FROM LITERATURE}

\subsection{Analysis in nominal stress of existing tests}

Only a few experimental works have been carried out by different authors on this connection and most tests were on CHS connections. The results from (Zirn, 1975), (JSSC 1969), (Harada 1982) and (Uchino 1974) can be obtained from a report issued by University of Karlsruhe (Mang et al, 1987). Table 1 is adapted from this publication and shows that to be conservative for slotted cases, a category 45 should be used, with $m=3$. The categories in this table and their limits correspond to the ones found in IIW, contradicting the values given in the Eurocode (and with different limits).

Table 1. Categories, details and description according to (Mang et al, 1987).

\begin{tabular}{|c|c|c|}
\hline $\begin{array}{l}\text { Fatigue } \\
\text { Category }\end{array}$ & Detail & Remarks \\
\hline 63 & (61) & $\begin{array}{l}\text { Tube-Plate connection } \\
\text { Slotted tube end connected to a plate } \\
\text { Limits: } \\
\text { Plate thickness } 20 \mathrm{~mm} \\
\text { Tube diameter } 200 \mathrm{~mm}\end{array}$ \\
\hline 45 & $(60)$ & $\begin{array}{l}\text { Tube-Plate connection } \\
\text { Slotted tube end connected to a plate } \\
\text { Limits: } \\
\text { Plate thickness } 20 \mathrm{~mm} \\
\text { Tube diameter } 200 \mathrm{~mm}\end{array}$ \\
\hline
\end{tabular}

Reanalysing the data of the last two authors (Harada and Uchino), we came to the conclusion that the results are very scattered and no detailed information on the test specimens could be found. The JSSC test results are more homogeneous but provide a relatively low bound and again no detailed information is available. Thus the largest, most coherent and complete dataset is still the one by Zirn from his original report (Zirn 1975). Concentrating on Zirn's, it can be noticed that most cracks started from the weld toe at the end of the gusset plate welded to the tube. All tests were carried out on CHS tubes with $d$ $=88.9 \mathrm{~mm}$ and plates $t_{\mathrm{p}} \leq 20 \mathrm{~mm}$. The end of the tube was systematically closed with sealing plates. Figure 3 shows the experimental results separated into two groups depending upon the chamfered angle of the tube. Comparing the test results with the curves from the Eurocode (CAT 71 for $\alpha \leq 45^{\circ}$ and 63 for $\alpha>45^{\circ}$ ), one notices that they are both unrepresentative and un-conservative. The characteristic curves (mean minus 2 std dev.) determined by linear regression were, respectively, CAT 80 with $\mathrm{m}=4.26$ and CAT 60 with $\mathrm{m}=3.91$. The difference that can be observed with the chamfering angle vanishes when using a slope $\mathrm{m}=3$ as shown in figure 3 . Higher slopes, often close or equal to $\mathrm{m}=5$, are often found when analysing fatigue data on tubular connections. The IIW category FAT 45 is, on the 
contrary, conservative, but not the FAT 63 which should be valid for $d \leq 200 \mathrm{~mm}, t_{\mathrm{p}} \leq 20 \mathrm{~mm}$. Different steel grades were tested but no significant difference could be seen when plotting the data.

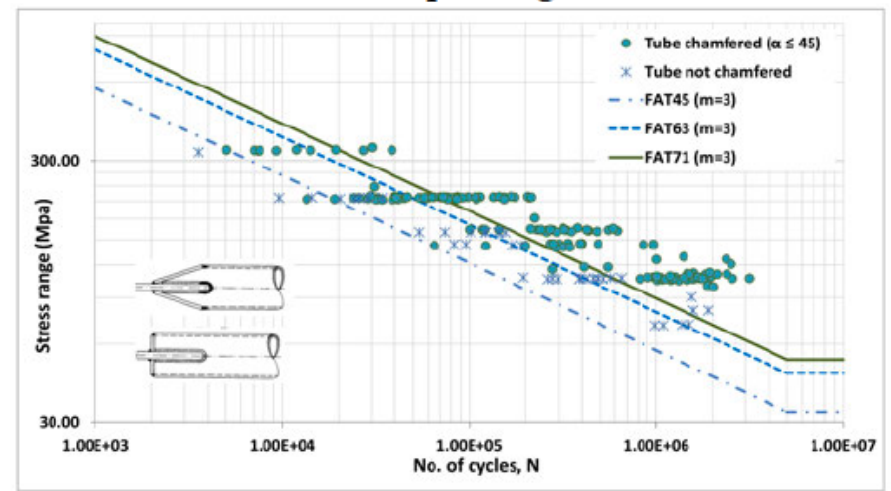

Figure 3. S-N plot in nominal stress of slotted tubular connections from Zirn, with code curves $(\mathrm{m}=3)$.

Figure 4 shows the experimental results separated into two groups depending upon the weld type. In this case, the difference is clearer, showing that this parameter is more important. We believe the reason lies in the higher stress concentration at the weld end in the case of fillet welds. Full penetration welds allow for a smoother stress flow from the tube to the plate, and vice-versa. Note that the slopes of the regression lines are again close to $\mathrm{m}=4$ leading to CAT 73 for full penetration welds, and CAT 55 for fillet welds. Fixing the slope to $\mathrm{m}=3$ gives CAT 56 for full penetration welds, and CAT 45 for fillet welds.

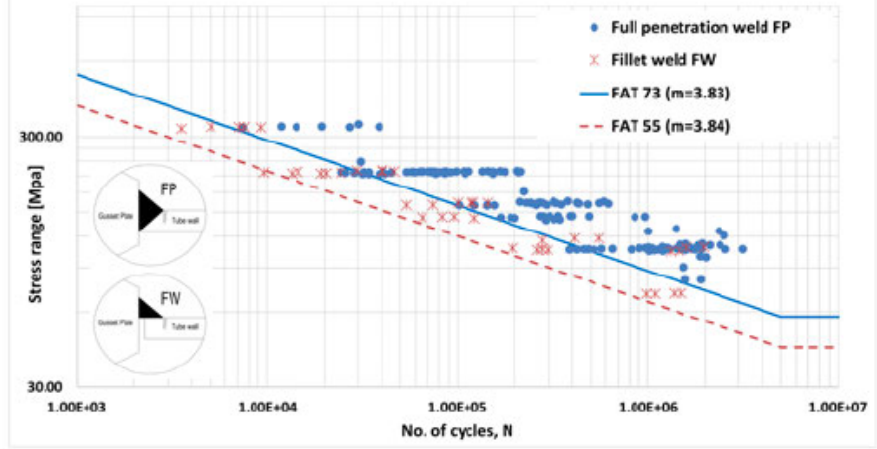

Figure 4. S-N plot in nominal stress of slotted tubular connections from Zirn, differentiating between weld types

More recently, Liu carried out a few fatigue experiments on this connection made with RHS and with slot gaps between the gusset plate and the tube (Liu 2006). He also found that the crack initiates from the beginning of the gusset plate, close to the slot gap, which is sharper than an open hole. Not surprisingly, his tests correspond to a characteristic valure at 2 million cycles of $36 \mathrm{MPa}, \mathrm{m}=3$, the lowest of all detail categories.

All of the above leads us to put into question the detail category, the differentiating parameter (chamfered angle) and the beneficial effect of an open hole (as shown in the Eurocode).

\section{FATIGUE ASSESSMENT OF THE DIFFERENT INDIVIDUAL DETAILS}

\subsection{Longitudinal attachment}

Before analysing the complete connection, it is important to understand the fatigue behaviour of the different details composing the connections, starting with longitudinal attachment, then with the influence of a hole.

A tube gusseted connection as shown in figure 5, is included in many codes. This connection is similar to a slotted tube to plate with the end of the loaded longitudinal attachment welded onto a tube. In this case cracking occurs in the tube - at the weld toe or in the weld end. However, there are two major differences regarding the stress field in the connection:

- the attachments and the tube are both welded to an endplate, the tube continues to carry its load share to the endplate,

- the tube is not slotted, thus the stress path between the tube and the attachments is smoother, closer to an unloaded longitudinal attachment.

Both these differences lead us to think that this detail shall have a better fatigue resistance then the slotted tubular connection. All the same, it is clearly shown that the plate geometry has strong influence and shall be made with a radius transition, which is not specified in the Eurocode for the slotted tubular connection.

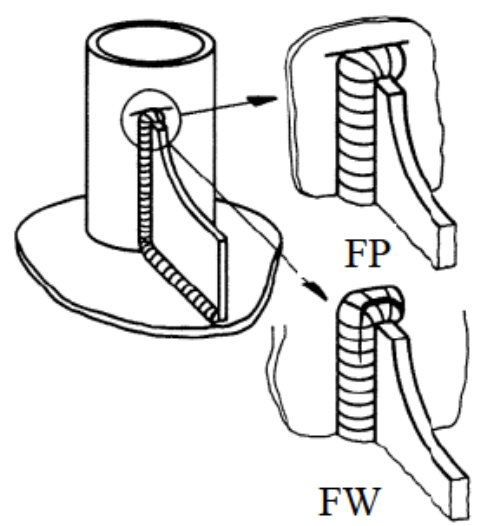

Figure 5. Illustration of tube gusseted connections (BS 7608, 1993).

DNV (DNV 2014) has detail categories varying from 90, with full penetration welds (FP), down to 71, with fillet welds (FW). The (BS7608 1993) has detail categories ranging from 68 for $\mathrm{FP}$ and failure in the tube at the weld toe, down to 43 for weld throat failure in fillet welded gusseted connections (FW), as illustrated in figure 5. DNV has higher categories but requires that the design stress include the stress concentration factor due to the overall form of the joint, which will lower the categories. In BS 7608, the design stress has to include any local bending stress adjacent to the weld end. This last point has more importance in this detail then in the 
slotted one since with the slot the plate is on both sides, there is less local bending. Overall, the codes do not have significantly higher categories for this detail compared to the slotted tubular connection, but the weld type is the main influencing parameter.

The notch stress method is directly applicable to this detail, but was outside of the scope of this study. Instead, the focus was directly set on modelling the complete slotted tubular connection as presented in the next section.

\subsection{Plate with hole in nominal stress}

The experimental results collected from literature for this detail, exemplify tests carried out in several leading European and American laboratories from 1960 to 2007 . They were carefully selected in order to limit the scope to experiments typical to steel bridges. Only tests above $110^{4}$ cycles, performed in plates under axial loading, and with the method of fabrication and crack path clearly specified were considered. The resulting data set is plotted in figure 6.

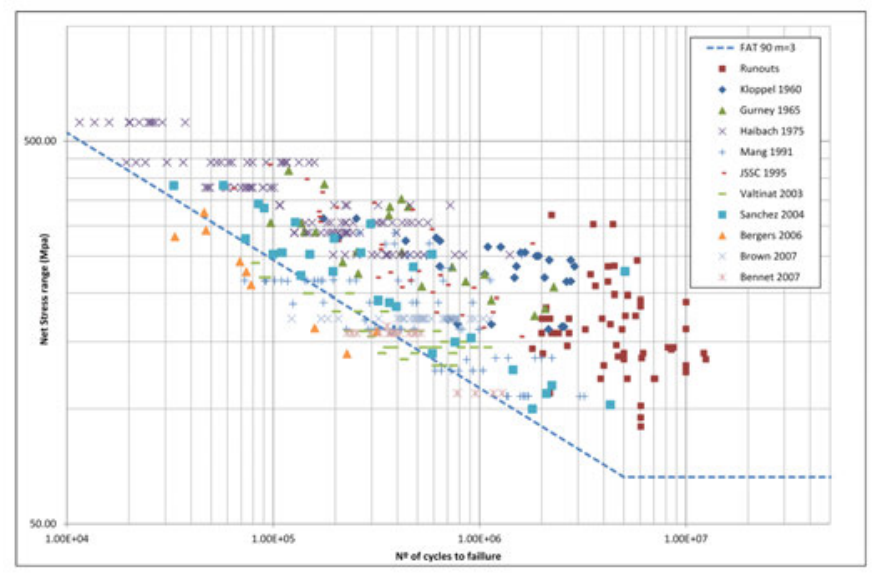

Figure 6: S-N plot in nominal stress of all results on plates with holes

Klöppel (Klöppel, K., Weihermüller 1960) performed tests in plates with drilled holes at 4 different stress ratios $(\mathrm{R})$ and showed a strong dependence on that parameter. The regression analysis shows a slope close to $\mathrm{m}=5$, which indicates a significant fatigue life spent in initiation.

Gurney (Gurney 1965) carried out fatigue tests on mild and high strength structural steel plates with a hole drilled and reamed. A remarkable dependence on steel type was observed with a slope also close to $\mathrm{m}=5$.

In (Haibach 1975) fatigue tests were reported on plates with drilled and reamed holes. Some dependence on R-ratio was observed but not on steel type.

Results presented in (Mang et al. 1991) refer to holes made by flame or plasma cut. Each plate had 3 holes spaced longitudinally at $150 \mathrm{~mm}$. Plate thickness of 12, 20 and $30 \mathrm{~mm}$ were investigated not showing any pronounced size effect. No effect was found for the steel grade (St 37, St 52 and St E690) which indicates that initiation life is small due to plasma and flame cut rugosity. Regression analysis shows slopes close to $m=3$ indicating that the fatigue life is fully in propagation. It is reported that flame cut results in a $30 \%$ reduction in fatigue strength compared to drilling.

Results from (JSSC 1995) are included in the background from Eurocode 3 and also here but no information is available regarding specimen dimension or steel type. Thus these results will not be used in the notch stress re-analysis.

Tests on galvanized plates with punched or drilled holes of $15 \mathrm{~mm}$ are presented in (Valtinat \& Huhn 2003). Tests on punched holes revealed that the cracks started at the edge where the punch goes in, propagating as a corner crack until the crack reached the edge on the opposite surface. This represented almost the entire life, i.e. the propagation as an edge crack (trough thickness) was very fast. The specimens with drilled holes showed cracks mainly initiated in the mid thickness of the plate, propagating as a semi-elliptical crack. The results for punched holes show a poorer fatigue performance than the drilled ones. The authors further conclude that galvanizing has also a negative effect on the fatigue resistance.

Further tests on plates with punched or drilled holes are reported in (Sánchez et al. 2004). Again punched hole specimens were shown to have much lower fatigue life than the drilled ones. Punched holes behave with slope around $\mathrm{m}=3$ while drilled ones with a slope around 5 . The fatigue crack for the punched specimens initiated at the transition point between the shear band and the tearing zones resulting from the punching process.

Fatigue tests in plates with plasma-cut holes were performed in (Bergers et al. 2006). Tests were done on steels S 460 MC, S 960 QL, S 1100 QL but no difference was found with the increase of steel grade. The results plot with a slope $\mathrm{m}=3$, indicating the predominance of propagation life due to the plasma cut surface defects. All cracks were reported to start in the inner edge of the hole.

Tests with holes done by punching, drilling or reaming are reported in (Bennett et al. 2007). The tests with drilled or reamed holes were all stopped around 2 million of cycles and considered run-outs. The fatigue performance of the punched ones was again very poor compared to drilled or reamed.

The results reported in (Brown et al. 2007) in punched and drilled holes are not included in the notch analysis because the hole on the finite width plates was not symmetrical and no clear information about each crack path is given.

Holes in plates are classified in Eurocode 3 as CAT 90 for the net cross-section nominal stress based on 3 sets of results (JSSC 1995; Valtinat \& Huhn 2003; Mang et al. 1991). However the reanalysis shows this FAT category to be non- 
conservative. Many authors report the results in terms of gross cross-section nominal stress, thus the results were converted using:

$\Delta \sigma_{\text {net }}=\Delta \sigma_{\text {gross }} \cdot\left(\frac{w}{w-d}\right)$

where $\mathrm{w}$ is the plate width and $\mathrm{d}$ is the hole diameter. The re-analysis of the data set shows that the fabrication method of the hole is the most remarkable parameter in plotting the fatigue results, see figure 7. Two different groups of holes were identified and regression analysis performed:

- Quality Group 1: Drilled and Reamed holes (Rz5 Range 1) - FAT90

(i.e. FAT 145 with slope $\mathrm{m}=3.03$ and characteristic FAT 97 with $\mathrm{m}=3$ )

- Quality Group 2: Punched, Flame and Plasma cut holes (Rz5 Range 2) - FAT71

(i.e. FAT 91 with slope $\mathrm{m}=2.62$ and characteristic FAT 69 with $\mathrm{m}=3$ )

Note: Rz5 is the ten-point roughness i.e., the average height from the five highest peaks and five lowest valleys over a given length (EN 9013).

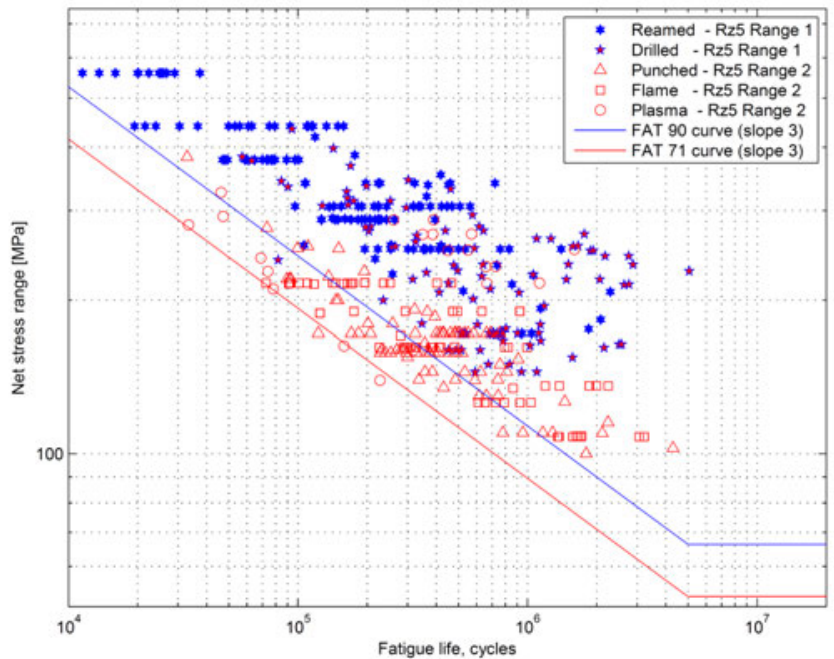

Figure 7: S-N plot in nominal net stress with classification in relation to the fabrication method of the hole

According to EN 1090-2, holes may be formed by any process (drilling, punching, laser, plasma or flame cut), with the requirement that the local hardness and quality of the cut surface be checked. For Execution Class 4 (EXC4), punching without reaming is not allowed. Local hardness values were measured by (Mang et al. 1991; Valtinat \& Huhn 2003) for punched, flame and plasma cut holes for example and they were inside the allowable range (380HV10 for steel up to S460 and 450HV10 for steel up to S690). Also residual stresses were measured but the values close to the hole edge were low. The most important parameter distinguishing the 2 groups is the surface roughness in the hole, which may eliminate the initiation life, and introduce severe notches that act like initial fatigue cracks. The limits of roughness are defined according to EN 1090-2 for the Execution Class 4 (EXC4) as
Range 2 quality for the mean height profile (Rz5) according to EN 9013, which means a maximum value of Rz5 $=40+(0.8 * \mathrm{t}[\mathrm{mm}])[\mu \mathrm{m}]$, which for the maximum plate thickness $\mathrm{t}=30 \mathrm{~mm}$, leads to $64 \mu \mathrm{m}$. As per the data set, surface quality was classified as Class 1 according to DIN 2310 in plasma cuts (Mang et al. 1991) which for $t=12 \mathrm{~mm}$ gives $\mathrm{Rz}=65 \mu \mathrm{m}$. We recommend thus that for EXC4, structures subjected to fatigue loads, the Range 1 be adopted $\mathrm{Rz} 5=10+(0.6 * \mathrm{t}[\mathrm{mm}])[\mu \mathrm{m}]$.

The characteristic fatigue curves that represent the lower bound of the data set results from figure 7 may also be obtained by a linear elastic fracture mechanics approach, accounting for the initiation life in the Quality Group 1. A review of similar models is described in (Radaj et al. 2006) and has been adopted for plates with holes in low cycle fatigue by (Sehitoglu 1983) or for several high-strength steel details by (Pijpers 2011). The resistance of steel to fatigue crack initiation includes nucleation and short crack growth. The initiation life is modelled with a method described in (Haibach 2006), details can be found in (Baptista 2014). The initiation period is completed when the microcrack growth is no longer dependent on the microstructure or surface conditions, and thus, the crack growth resistance of the material starts to control the crack growth. The size of the microcrack at the transition stage is thus material dependant. We adopted the Range 2 limit Rz5 $=40+(0.8 \times t[\mathrm{~mm}])[\mu \mathrm{m}]$, which for the maximum plate thickness $t=30 \mathrm{~mm}$, leads to $64 \mu \mathrm{m}$.

Linear Elastic Fracture Mechanics is used for the propagation stage. Two types of cracks have to be considered to propagate the initial crack to a through-thickness crack. Observations of the failure surfaces of cracked specimens have shown that cracks propagate in this stage as corner crack or semi-elliptical cracks. Tests on punched holes revealed that the cracks started at the edge where the punch goes in, propagating as a corner crack until the crack reached the edge on the opposite surface. The specimens with drilled holes showed cracks mainly initiating in the mid-thickness of the plate, propagating as a semi-elliptical crack. In the final propagation stage, LEFM is used to propagate a through-thickness edge crack. For modelling the total life, two cases are compared:

- Quality Group 1 (QG1): Initiation, propagation first as semi-elliptical and final propagation as through-thickness crack

- Quality Group 2 (CG2): Propagation first as corner crack and final propagation as throughthickness crack.

The stress intensity factor expressions used for the corner crack, semi-elliptical and throughthickness crack are detailed in (Baptista 2014). The results for CG2 are shown for example in figure 8. The cloud of points is close to the characteristic curve 71 for QG2, which shows that the model is 
able to properly reproduce the lower bound of the quality group. The same can be said for QG1 and characteristic curve 90 . The proposed detail categories are thus confirmed to be FAT 90 for QG1 (drilled and reamed holes) and FAT 71 for QG2 (Punched, Flame and Plasma cut holes).

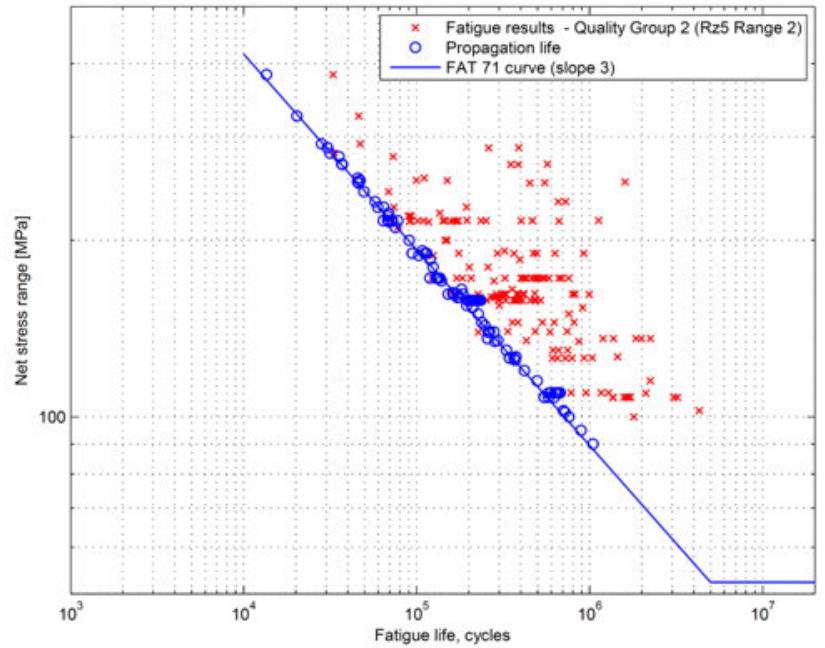

Figure 8: Comparison in nominal stress between experimental data set and model for Quality Group 2, only propagation stage considered.

\subsection{Plate with hole in notch stress}

The data set is transformed into notch stress by considering the stress concentration factors corresponding to the plate and hole geometries (Peterson 1997). The resulting plot is shown in figure 9. The proposed characteristic curves for each of the two quality groups are also drawn. It can be seen that for QG1, the use of a FAT 225, $\mathrm{m}=3$, is appropriate. This is not the case for QG2, where only a FAT 170 should be used.

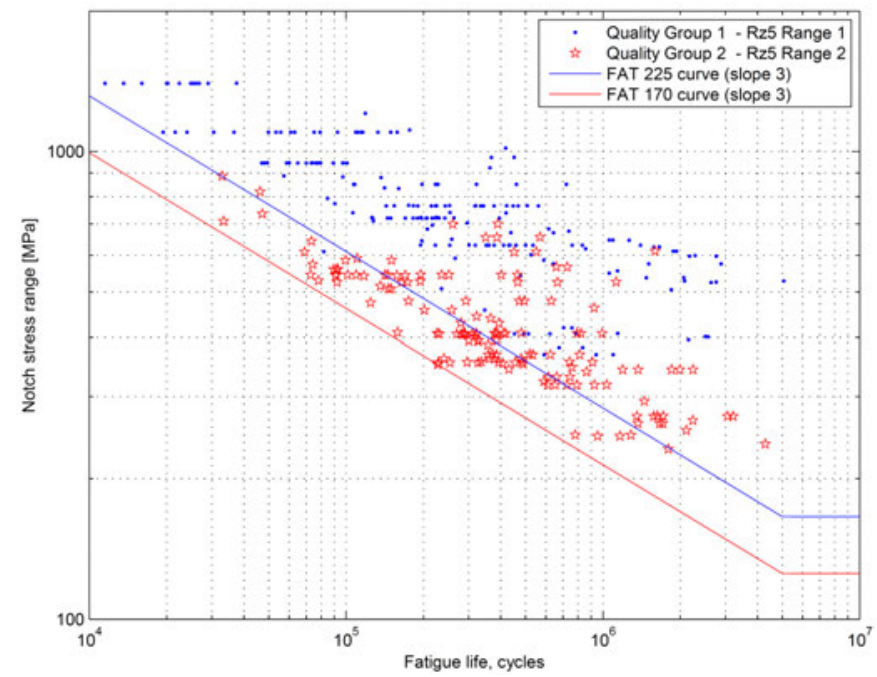

Figure 9: Comparison in notch stress between experimental data set and characteristic reference fatigue curves proposed

For more complex details, the net cross-section nominal stress to gross stress ratio is not uniquely defined, i.e. there is no direct geometric relation between the hole and elements composing the connection. The stress concentration factor varies with the many geometrical parameters, so that different $K_{\mathrm{f}}$ can be found for the same level of gross or net crosssection nominal stress. Thus it is only possible to determine a stress value with a FEA coupled with a Hot Spot or Notch Stress analysis.

It should be mentioned that while the analysis of the entire data set does not show any influence of the steel grade, a remarkable difference is noticed for the results of QG1, which indirectly indicates once again the importance of the initiation life in drilled and reamed holes.

\subsection{Complete connection}

The FEA was carried out on a series of models representing the slotted tubular connections tested by Zirn, see table 2, using the software ABAQUS. In all the tests reexamined and models, the tube is a CHS $88.9 \times 5$ and the attached plate thickness is $15 \mathrm{~mm}$. Zirn specimens have sealing plates at the end of the tube. To see the influence of this feature, since the cost of preparing/welding these plates is not negligible, both cases were modelled. The differences in the specimens concern the type of weld, the plate and tube chamfer. Another feature, not tested by Zirn, was added to the geometry in a series of models, the presence of an open hole at the end of the slot. The hole radius was chosen to be $17.5 \mathrm{~mm}$ (half the plate thickness plus twice the weld leg length). A couple of cases with elongated holes were also made. In total, with the different parameters included in the models, the number of runs was 34 .

All model results, given as $K_{\mathrm{f}}$ values, can be found in Table 2. An important limitation in the models is related to the initiation sites considered. At this time, since the main potential crack location observed in the tests is the cracking in the tube at the weld toe, and in one series of models where the open hole was added (and considered the new potential crack location), only these two were considered (i.e. the crack from the root or in the plate are not considered). The stress concentration factors (related to the nominal stress in the tube) for the different models (at the two details) are summarized in table 2. Note that the quality group requirement (QG1) for the open hole is important as the notch stress curve depends on it.

\section{COMPARISON AND DISCUSSION}

From the $K_{\mathrm{f}}$ values given in Table 2, one can deduce that for the same geometry, fillet welded connections have higher $K_{\mathrm{f}}$ compared to full penetration ones. The connections with sealing plates have a better resistance (i.e. a lower $K_{\mathrm{f}}$ ) then those without them, the sealing plates make the tube carry some load over to the plate without overstressing the attachment ends in the tube. 
Table 2. FEA geometries and resulting notch stress.

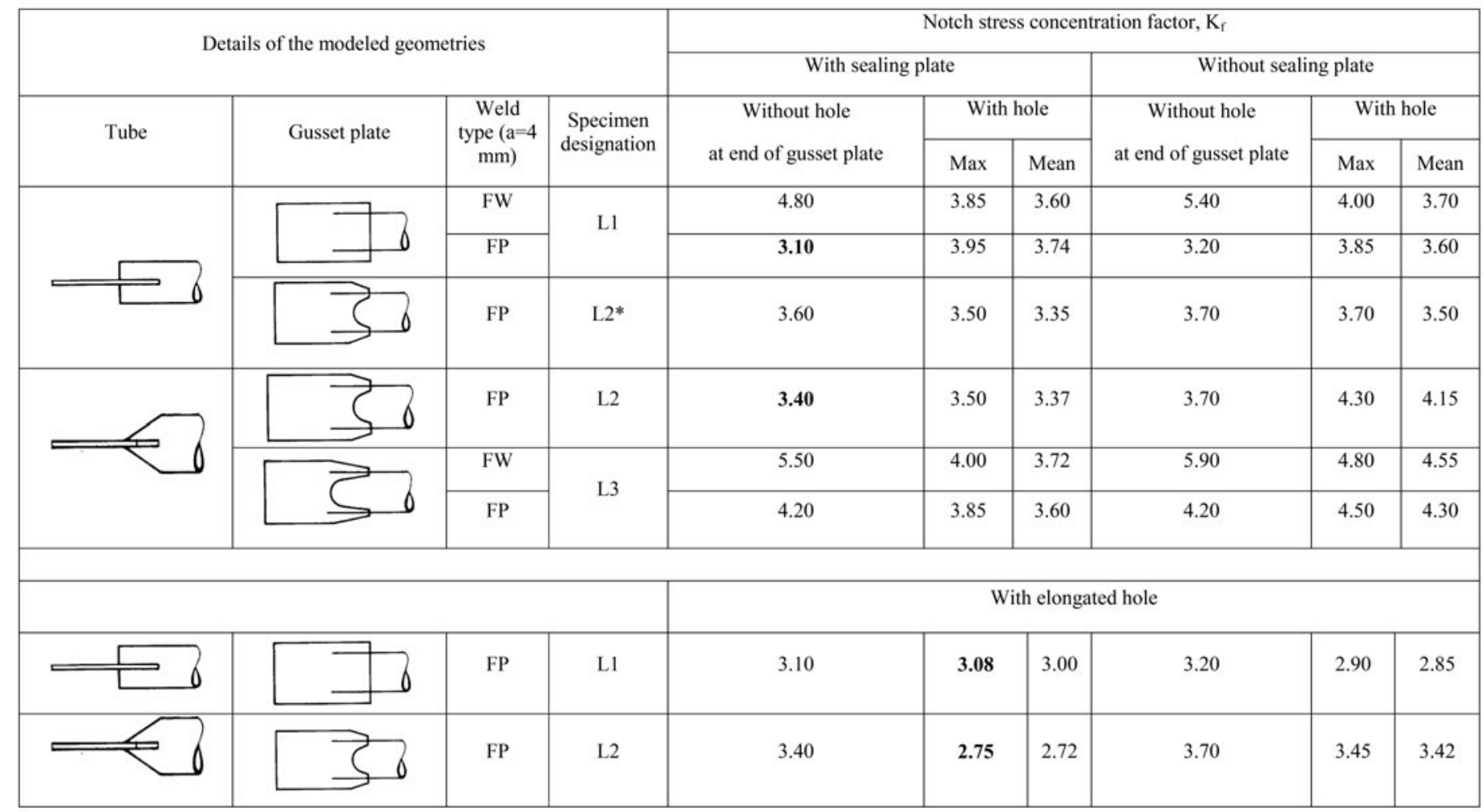

Table 3. Fatigue classes in nominal stress deduced from notch analysis, cases with sealing plates

\begin{tabular}{|c|c|c|c|}
\hline Case & $\begin{array}{c}\text { FEA } \\
\text { w/o hole }\end{array}$ & $\begin{array}{c}\text { FEA w/hole } \\
\text { Quality Group 1 }\end{array}$ & $\begin{array}{c}\text { FEA w/hole } \\
\text { Quality Group 2 }\end{array}$ \\
\hline L1_FW & 47 & $\mathbf{5 8}$ & 44 \\
\hline L1_FP & $\mathbf{7 3}$ & 57 & 43 \\
\hline L2*_FP & $\mathbf{6 4}$ & 64 & 48 \\
\hline L2_FP & $\mathbf{6 6}$ & 64 & 48 \\
\hline L3_FW & 41 & $\mathbf{5 6}$ & 43 \\
\hline L3_FP & $\mathbf{5 4}$ & 58 & 44 \\
\hline elongated & & & \\
\hline L2*_FP_el & 73 & $\mathbf{7 3}$ & 55 \\
\hline L2_FP-el & 66 & $\mathbf{8 2}$ & 62 \\
\hline
\end{tabular}

For the cases with holes, note that both max value anywhere along the hole edge (not chamfered in the models) as well as the average value are given. The authors have used the max. values herein to be conservative, one could however argue that the average is more representative of well executed holes. The two models with elongated holes show it is an effective solution: the crack potential location remains inspectable in the hole edge, while the Stress Concentration Factor is lower than a circular hole.

Since the studied geometries are very close, a direct comparison between the different cases can be made in nominal stress (in the tube), taking into account the proper reference notch fatigue curves for the calculated notch factors; in other words, one can divide the FAT value by $K_{\mathrm{f}}$. The reference notch fatigue curves, corresponding to characteristic values, are FAT 225 for the welds and FAT 170 for the holes, because usually the slot and hole are made by the same fabrication method and correspond to QG2. The results are shown in Table 3 . It can be seen that Full Penetration welds may be considered in a CAT63 (except for geometry L3). In these connections, introducing the hole is even detrimental to the fatigue resistance to the whole connection, unless elongated holes in QG1 are adopted. In geometry L3, the chamfering of the plate is seen to be excessive and leads to an increase of the concentration at the weld in the tube. For Fillet Welded connections, CAT 45 is suited while the hole may increase the resistance to CAT 56 if holes are made in QG1.

Finally, one can plot Zirn results in notch stress, see Figure 10. It shows the capacity of the notch method to describe different notch cases as the difference between PP and FW is diluted in a global notch scatter band. One can note that the slope $\mathrm{m}=4$ is more adequate and, logically, confirms the analysis on figure 4 in nominal stress.

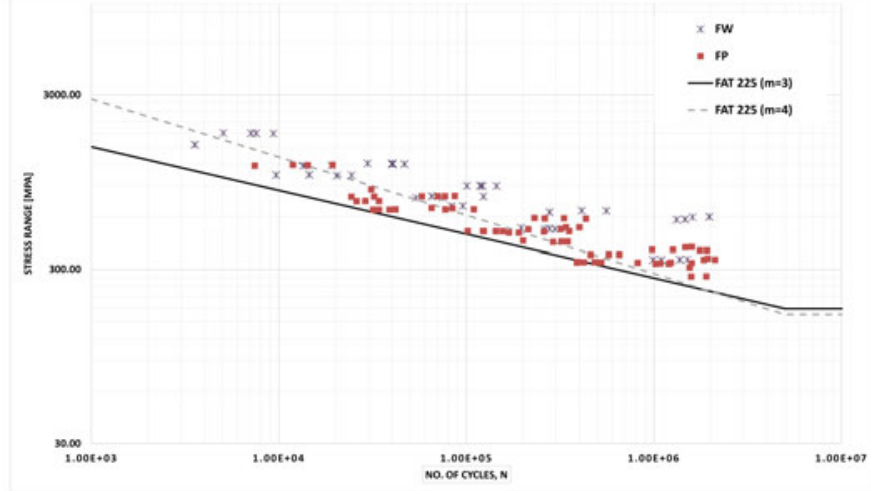

Figure 10: Comparison in notch stress between experimental data set and characteristic reference fatigue curves proposed 


\section{REFERENCES}

\section{DETAIL RECOMMENDATIONS}

The connection types with full penetration welds have a better fatigue resistance and thus should be promoted. The presence of sealing plates is also beneficial. Regarding the chamfering of the tube, it has limited influence on the fatigue resistance as long as full penetration welds are used. The same can probably be said for the chamfering of the plate, but was not fully studied; the chamfering of the part of the plate inside the tube is of more significance.

Open holes can be a good solution for tolerance reasons and NDT in order to avoid a non-detectable crack starting from weld root. But if the connection contains open holes, it is recommended to adopt the quality group 1 , which corresponds to a maximum roughness of $\mathrm{Rz} 5=10+(0.6 * \mathrm{t}[\mathrm{mm}])[\mu \mathrm{m}]$. If only the quality group 2 is used because it may not be economical to ream holes after cutting them together with the slit, or to drill them separately from the slot, then a solution could be to put an elongated hole in the stress direction instead of a circular one. If one uses an elongated hole with a length double its width, the improvement can be expressed by using $0.81 K_{\mathrm{f}}$ (or by multiplying the fatigue class with $1 / 0.81$ ) which approx. compensates for cut quality group 2 instead of 1.

\section{CONCLUSION}

The following conclusions can be drawn:

- For plates with holes, only drilled and reamed holes (Rz5 Range 1) can achieve FAT 90 in nominal net stress, and FAT 225 in notch stress (Quality Group 1). For Quality Group 2, the values are FAT 71 in nominal net stress, and FAT 170 in notch stress.

- The fatigue categories in Eurocode 3, part 1.9, for the slotted tubular connection should be updated in terms of fatigue strength, requirements and drawing of potential crack location(s).

- The connection types with full penetration (FP) welds have a better fatigue resistance and the weld type, which is one main influencing parameter, should be considered in the codes (may be instead of chamfering angle of the tube). This study shows they could be classified in CAT 63 for FP and CAT 45 for FW.

- The presence of sealing plates is beneficial to the fatigue resistance. So is the presence of the hole, but only for fillet welded plates.

- The notch method (FAT 225) is able to include the difference between FP and FW notch cases.
Fisher, J. W. 2009, June 4. Prof., Lehigh Univ., USA, Private communication.

DNVGL-RP-0005. 2014, June. RP-C203: Fatigue design of offshore steel structures, http://www.dnvgl.com.

Mang, F., Bucak, \& Klingler, J. (1987). Wöhlerlinien katalog für Hohlprofilverbidungen. Universität Karlsruhe: Studiengesellschaft für Anwendungstechnik von Eisen und Stahl e.V.

Liu, Y., Dawe, J., \& Li, L. (2006). Experimental study of gusset plate connections for tubular bracing. Journal of Constructional Steel Research, 62, 132-143.

Zirn, R. (1975). Schwingfestigkeitsverhalten geschweißter Rohrknotenpunkte und Rohrlaschenverbindungen. Stuttgart: University of Stuttgart.

Fricke, W. et al. 2002. Comparative fatigue strength assessment of a structural detail in a containership using various approaches of classification societies. Marine Structures, 15(1), pp.1-13.

Fricke, W. (2008). Guideline for the fatigue assessment by notch stress analysis for welded structures. International Institute of Welding.

Fricke, W. 2012. IIW Guideline for the Assessment of Weld Root Fatigue. International Institute of Welding.

Hobbacher, A. (1996). Fatigue Design of Welded Joints and Components. Cambridge (UK): Abington Publishing, $1^{\text {st }}$ ed.

Radaj, D. (1990). Design and Analysis of Fatigue Resistant Structures . Abington Publishing, Cambridge (UK).

Niemi, E., Fricke, W. \& Maddox, S.I. (2006). Fatigue analysis of welded components, Woodhead Publishing Limited.

Radaj, D., Sonsino, C. \& Fricke, W. (2006). Fatigue assessment of welded joints by local approaches, CRC.

Baptista, C. (2014). A reanalysis of the fatigue strength of steel plates with holes, EPFL report $\mathrm{N}^{\circ}$ 201786, ICOM-EPFL, Lausanne, 2014.

Bennett, C.R., Swanson, J.A. \& Linzell, D.G., 2007. Fatigue Resistance of HPS-485W Continuous Plate with Punched Holes. Journal of Bridge Engineering, 12(1), pp.98-104.

Bergers, J. et al., 2006. Beurteilung des Ermüdungsverhaltens von Krankonstruktionen bei Einsatz hoch- und ultrahochfester Stähle. Stahlbau, 75(11), pp.897-915.

Brown, J.D. et al., 2007. Evaluation of Influence of Hole Making Upon the Performance of Structural Steel Plates and Connections.

Gurney, T., 1965. Some Exploratory Fatigue Tests on Notched Mild and High Tensile Steels. British Welding Journal, 12(9), p.457/61.

Haibach, E., 1975. EUR5357 - Fatigue investigation of higher strength structural steels in notched and in welded condition,

JSSC, 1995. Fatigue design recommendations for steel structures J. S. of S. Construction., ed.,

Klöppel, K., Weihermüller, H., 1960. Dauerfestigkeitsversuche mit Schweißverbindungen aus St. 52. Stahlbau, 29(5), p.129/37.

Mang, F., Bucak, O. \& Obert, K., 1991. Investigation into the fatigue life of specimens with flame-cut holes and plasma cutting of steel. In New Advances in Welding and Allied Processes: Proceedings of the International IIW Conference. Beijing, China: IIW.

Sánchez, L., Gutiérrez-Solana, F. \& Pesquera, D., 2004. Fatigue behaviour of punched structural plates. Engineering Failure Analysis, 11(5), pp.751-764.

Valtinat, G. \& Huhn, H., 2003. Festigkeitssteigerung von Schraubenverbindungen bei ermüdungsbeanspruchten, feuerverzinkten Stahlkonstruktionen. Stahlbau, 72(10), pp.715-724. 